\title{
A modo de preámbulo
}

Juan Filópono, comentarista que vivió en el s. VI dC, nos ha conservado un fragmento - que algunos críticos atribuyen al mismísimo Aristóteles- en el que se narra cómo apareció entre los hombres la sabiduría y, por ende, la filosofía.

Cuenta Filópono - siguiendo la tradición que en Grecia recogen los mitos, los filósofos y los historiadores- que la humanidad sufría periódicannente cataclismos que acarreaban su destrucción casi total, quedando los escasos supervivientes en situación de extrema penuria y en la necesidad de volver a inventar la civilización. Y quienes, con su ingenio, supieron en aquellos momentos aportar soluciones o inventar artilugios para subvenir a las más perentorias necesidades, recibicron el nombre de sabios.

Con posterioridad fueron también llamados sabios quienes contribuyeron a mejorar las condiciones de vida, a embelleccrla y a conferirle un ordenamiento moral y político. Más adelante se consideró sabios a los hombres que se dedicaron a la observación de la naturaleza y a descubrir sus leyes; y por último fueron sabios quienes se aplicaron a la contemplación de las verdades supramundanas e inmutables.

En la categoría de sabio quedan, pues, incluidos los expertos en las más diferentes técnicas: desde el inventor de la agricultura o el arado, el inventor del alfabeto y los números, el médico, el poeta, el profeta, el astrólogo y el escultor, hasta el juez, el legislador, el fisiólogo, el geógrafo, el matcmático y, en último término, el filósofo que se dedica a la vida contemplativa.

En otro pasajc del comienzo de la Metafisica, que podría parecer complementario del que acabamos de citar, dice Aristótcles que para acceder a los últimos, y posiblemente más prestigiosos, estadios de la sabiduría - a saher los de la ciencia de la naturaleza y de la metafísica- es importante poder disfrutar de ocio. De modo que los nivcles más elevados del conocimiento quedan ligados a la ausencia de trabajo manual o de actividad profesional.

Pero en el reparto de funciones entre los sexos que conlleva la estructura de la sociedad gricga antigua, de todas estas artes o sabiduxías lc tocaron a la mujer, a parte de su función central reproductora, y estrechamente relacionados con ella, tan sólo el arte de tejer y el de la alimentación. De manera excepcional, y únicamente cuando la edad la dispensaba de la labor genésica, podía la mujer tener acceso a la palabra profética. 
El ocio y la disponibilidad de tiempo tuvieron, pues, para la mujer, en el ámbito de la Grecia Antigua, una lecrura completamente distinta que para el varón. Si en ćstc propiciaban actividades del más alto nivel intelectual o moral, a la mujer ociosa se la suponía entregada a fantasías eróticas que, como en los casus de una Helena o una Fedra, conducían a situaciones desventuradas tanto para ellas como para los demás.

Es por ello que las muchachas, o las mujeres con un marido ausente como Penélope, que por su condición disponían de muchas horas libres para el ensueño, debían mantener dedos y mentes ocupados en cl tclar, para evitar el vagabundeo de pensamientos y acciones susceptibles de acarrear funestas consecuencias.

La mujer sólo llegaba a serlo de verdad si se casaba: las cstclas funcrarias de las muchachas griegas están llenas de lamentos porque la muerte prematura las privó del matrimonio. Y el matrinonio, cuyos objetivos eran la procreación de hijos legítimos y la conservación del peculio, requería de la presencia estable de la mujer en el hogar.

Por este motivo aquellas actividades fruto de la imaginación, la habilidad, la inteligencia o el valor, que en la mujer comportaban el extrañamiento del hogar, conferian a ésta, si las practicaba, una cierta perversidad, y la colocaban en una situación marginal, que aunque podía reportarle atisbos de felicidad o de gloria solía tener un final desdichado.

Mas a pesar de este rígido entorno, hay momentos y lugares - nos agrada pensarlo- en que las mujeres de la Antigua Grecia alcanzaron algunos espacios de libertad para su imaginación. El círculo de Safo, en Lesbos, por ejemplo, es un lugar en que las doncellas, antes de volver al oikos y a los límites del matrimonio, expresaron intensamente su afectividad en un afán de belleza y de conocimiento.

También Teano de Crotona, filósofa y poeta, esposa de Pitágoras, trató de demostrar como la educación y el cultivo de las capacidades intelectuales y morales de la mujer no eran forzosamente ejercicios peligrosos, sino elementos que contribuían a mejorar el desempeño de su función en el oikos.

Siglos más tarde, en la época helenística, cuando la sociedad se hizo más cosmopolita y abierta, la mujer alcanzó a salir de su confinamiento en lo más profundo de la casa. Fueron abriéndose para ella nuevos ámbitos, obtuvo mayor capacidad jurídica y pudo acceder a la literatura, la filosofía, la ciencia, e incluso la política, eso sí, siempre de forma minoritaria y sin que su actividad se viera por completo libre de los antiguos prejuicios.

Estas consideraciones, que muy sucintamente tratan de evocar los límites que ya desde antiguo mantuvieron en la penumbra el saber de las mujeres, sirvan de preámbulo a las reflexiones que confluyen en este número de ENRAHONAR, y que nos invitan a mirar el pasado desde el presente o, casi mejor, tal como prefiere Nicole Loraux, el pasado en el presente.

Los trabajos que presentamos pueden agruparse en tres apartados: una introducción sobre la mujer como sujeto de la historia; una serie de artículos sobre sophia y mujeres en la Grecia Antigua, juntamente con la traducción de 
los textos de una pitagórica; y una tercera parte en la que figuran sendos artículos sobre Simone Weil y Hannah Arendt, filósofas contcmporáncas para quienes, quizás de modo algo paradójico, el mundo griego constituye un ámbito de adhesión que responde a la búsqueda de un espacio vital donde arraigat su palabra en el tiempo (Weil) o de un espacio de aparición de la visibilidad donde se hace posible desarrollar un pensar "sin barandillas" (Arendt).

Montserrat Jufresa

Editota 